Philosophy with Children, self-regulation and engaged participation for children with emotional-behavioural and social communication needs

Claire Cassidy*; Helen Marwick; Lynn Deeney; Gillian McLean

*Corresponding author

claire.cassidy@strath.ac.uk School of Education, University of Strathclyde, 141 St. James Road, Glasgow G4 0LT. 01414448036

Helen Marwick 2: helen.marwick@strath.ac.uk School of Education, University of Strathclyde, 141 St. James Road, Glasgow G4 0LT. 01414448073

Lynn Deeney: 1ynndeeney@,btinternet.com Local Authority Teacher

Gillian McLean: gmcleanrome@gmail.com Local Authority Teacher

(8,167 words including references and figures) 
Philosophy with Children, self-regulation and engaged participation for children with emotional-behavioural and social communication needs

\begin{abstract}
This study examined the effectiveness of Community of Philosophical Inquiry (CoPI) as an inclusive pedagogical approach by which to support the communicative interaction and opportunities for collaborative dialogue for children with social, emotional and behavioural needs in two mainstream classes. There is currently no empirical work that considers children with these particular needs participating in practical philosophy, particularly in CoPI. Two groups of children, aged between nine and twelve, engaged in CoPI over a period of ten weeks. The philosophy sessions were conducted as part of the regular class work. The results show that the children were able to engage in collaborative, philosophical dialogue with their peers without being any more disruptive than their classmates. The findings of this study lead to the assertion that it is the structure of CoPI that supported the children's engaged participation and self-regulation and that this might usefully be considered in creating classroom activities for all children.
\end{abstract}

Keywords: Autism; SEBN; Philosophy with Children; self-regulation; social engagement

\title{
Introduction
}

Consideration of children's physical and emotional well-being is paramount in current Scottish (Scottish Executive 2004; Scottish Government 2012), English (Department of Education, 2016) and broader international (e.g. OECD 2009; UNICEF 2013; Education Review Office, 2016; Ontario Ministry of Education, 2016) curricular documentation and other associated policies. Concomitant with this is the acknowledgment of the need for the implementation of effective inclusive pedagogy and practices to support a high quality social 
and educational experience for all children in an educational setting (Education Scotland 2010; OECD 2012).

The study that this article describes is situated in Scotland, and it should be noted at the outset that Scottish education is distinct in terms of curriculum, policy, law and practice from the other jurisdictions in the UK. The concept of Additional Support Needs (ASN) in Scotland recognises that social factors impact significantly on children's learning and, while the term ASN covers children who have needs arising from specific diagnosed conditions such as dyslexia or Autistic Spectrum Disorder (ASD), it also addresses the support needed for children experiencing a range of varied circumstances, such as those children who have English as an additional language, children who have been absent from school for a period of time, or children who are Looked-After (Moscardini 2013). There is a risk that children with ASN may be marginalised socially or disadvantaged academically; it is therefore essential that all children are provided with opportunities to learn and develop as far as possible in an inclusive environment.

The most frequently identified ASN in Scottish schools are Social, Emotional, and Behavioural Needs (SEBN) (Marwick and Sosu 2014). Children identified as having SEBN have been observed to experience poor quality relationships and interactions with other children and adults in the school, experiencing negative emotions and lack of engagement in class activities (Layard and Dunn 2009; HMIE 2011; Department for Education (DfE) 2016). Children diagnosed as being on the autism spectrum may also experience difficulties in social interaction, communication and perspective-taking (Volkmar et al. 2014), and an inclusive pedagogy would be responsive to the differences in cognitive, interpersonal, perceptual and sensory processing which may be experienced. If unmet through a responsive educational 
environment, such difficulties can lead to lowered educational outcomes and reduced wellbeing (Humphrey et al. 2015).

The benefits of engagement in responsive and facilitative activities which promote interpersonal connection and perspective-taking are applicable to the developmental outcomes for all children, and activities which could support these abilities in children identified as having SEBN, and children diagnosed with autism spectrum disorder (ASD) would be of marked value. Philosophy with Children $(\mathrm{PwC})$ is an approach which aims to develop interpersonal understanding and perspective-taking through facilitated, structured dialogue. The aims of $\mathrm{PwC}$ include listening to, taking account of, and making connections with others' perspectives; the promotion of what Lipman (2003) refers to as critical, creative and caring thinking. These are features that children with SEBN and children with ASD may find challenging, but at the same time, $\mathrm{PwC}$ also incorporates a structured and predictable format of interaction, which might support the needs of these children, as clear communication, specific and achievable behavioural requirements and expectations, and experience of peer modelling are recommended to help support engagement, empathy and confidence for children with SEBN (Cooper and Cefai 2013). Additionally, rule based conversational structure and consistency can support communicative engagement and pragmatic understanding for children with ASD (Quill 1995).

\section{Philosophy with Children}

Gregory (2008) outlines what is central to $\mathrm{PwC}$, describing the cognitive features that are developed through the practice: creating hypotheses; clarifying terms; giving and evaluating reasons; offering examples and counter examples; questioning assumptions; drawing inferences; sharing perspectives; listening attentively; helping others make a point; and challenging and building on other people's ideas. While there is a range of approaches to 
$\mathrm{PwC}$, there is clear commonality in the findings of studies investigating the impact of these practices in a range of settings internationally (García-Moriyón et al. 2005; Daniel and Auriac 2011; Millett and Tapper 2011; Cassidy and Christie 2014; Gorard, Siddiqui and Huat See 2015). The results from such studies with typically developing children have reported, amongst other things, high engagement and the demonstration of enhanced attention and perspective-taking abilities.

Within the curriculum, $\mathrm{PwC}$ has been shown to support particular skills or abilities. In their meta-analysis of over one hundred studies, García-Moriyón et al. (2005) identified that PwC has benefits in developing children's higher order thinking. Daniel (2008) also found higher order thinking improved as a consequence of $\mathrm{PwC}$, asserting that after participation in a programme of $\mathrm{PwC}$ the 'dialogical and cognitive competencies of pupils ... succeeded in surpassing the anecdotal and monological exchange in which they were situated at the beginning of the school year' (46). Cassidy and Christie (2014) demonstrate that children's reason-giving improves after only ten weeks of hourly Community of Philosophical Inquiry (CoPI) sessions and Topping and Trickey (2007a) report cognitive gains for children who participated in their philosophy sessions, with follow-up work showing that two years later the children had maintained the gains they had achieved over their peers (2007b). Millett and Tapper (2011) illustrate that in the Australian context there is similar evidence of cognitive gains from $\mathrm{PwC}$, but also, that there have been positive effects on 'student engagement with learning, active listening, and evidence of more care and respect in student-to-student interactions' (12). This echoes Lipman's (1988) claims, that participation in PwC supports children's social development. Daniel (2008) has also shown that children's social skills and social commitment developed and that 'their judgement and their representations of emotions and of violence... transcended the egocentricity of this age group' (46). In subsequent work, Daniel and Auriac (2011) explain that the demands of $\mathrm{PwC}$ are such that 'it calls upon 
complex cognitive and social skills, these being constant attention to the words of the other and a surpassing of oneself in the search for questioning that holds meaning' (422). It is also worth noting that there is evidence of children in mainstream classes experiencing gains in the affective domain as a consequence of participating in PwC (Trickey 2008; Cassidy and Christie 2014; Gorard et al. 2015). The case for employing PwC to promote empathy in children is presented by Schertz (2007) who argues that children 'need practice in imagining/perceiving another's perspective' (191). He goes on to say that this is achieved through dialogue as it requires participants to engage with one another in order that both, or all, will 'grow' as a consequence. He provides examples from his experience of children using the inquiry approach to resolve disputes amongst themselves beyond the normal confines of the classroom and its goals; this is echoed in Cassidy and Christie's 2014 study.

In considering teacher/pupil dialogue, Topping and Trickey (2014) assert that if children engage in well-structured tasks that demand collaborative working, they will exhibit more ontask behaviour. Christie et al. (2009) identify, however, that teachers do not always consciously plan tasks in ways that necessitate collaboration; some assume that collaboration will occur simply by placing children together. $\mathrm{PwC}$, however, demands and promotes collaboration as essential to the practice. Schertz (2007) suggests that children will be more engaged in a community of inquiry approach like PwC because they, rather than having views of adults imposed on them, have the opportunity to explore their own ideas and their 'contributions shape the evolution of the dialogue' (196).

In Community of Philosophical Inquiry (CoPI) (McCall 1991, 2009; Cassidy 2007, 2012) the children begin by reading a stimulus text and then ask questions provoked by the stimulus. After noting the questions, the facilitator selects the question for the dialogue. This offers 
participants ownership of the dialogue; they will be invested in the topic since it has been derived from the shared experience of the stimulus and from within their community. While the children do not select the specific question for discussion, since the facilitator has the philosophical background that ensures she recognises which question has the greatest philosophical potential (Cassidy 2012), the question belongs to the group rather than it being provided for them. Additionally, the clear set of rules that provide the structure that a CoPI session follows means that all children know what to expect in terms of the session format. This affords some security for children who require support in social contexts.

\section{The research problem}

While the evidence of effectiveness of PwC for the social, emotional and cognitive developmental skills of children in classrooms generally may be compelling, for those with ASD and difficulties in relation to their social and emotional behaviour, the demands of this type of on-task group behaviour could be considered more challenging. Children with autism can find the pragmatics of conversations difficult, such as turn-taking conventions, initiating and terminating conversational turns, matching the content and detail of a conversational contribution with the context of the conversation, and coping with multiple conversational partners (Wing 1996; Landa 2000). A child with SEBN can be understood to have difficulty predicting the emotional and behavioural response of another person, in attending to another person or multiple conversational partners, and in matching the emotional content of their conversational turn to the context (Lyons-Ruth 1996; Cooper and Cefai 2013). Nevertheless, it could be argued that the very specific structure of the $\mathrm{PwC}$ approach may actually support these social processes in children with SEBN, or in children with autism, who could benefit from the clearly embedded rules in relation to turn-taking, the format of conversational contributions, and predictable discourse parameters of the interaction. This would seem to articulate with Idsoe's (2016) suggestion that a learning environment needs to be created that 
'promotes inclusion and caring and supportive interpersonal relationships' (163) where behavioural expectations are clear.

None of the studies noted above report specifically on working with children with ASN in the areas of ASD and SEBN. This study, therefore, aimed to examine how useful the CoPI approach might be for children identified as having SEBN or autism. In particular, we wanted to explore whether CoPI supports children's engaged participation and their selfregulation in the activity. Given previous research in the area, we also wanted to gauge whether engagement or self-regulatory behaviours presented in the CoPI sessions would transfer to other social or academic situations for the children. This led to three specific research questions:

1. Can children with autism and/or emotional-behavioural needs engage with CoPI?

2. Does CoPI affect self-regulation for children with autism and/or emotionalbehavioural needs within CoPI sessions?

3. Does behaviour in CoPI transfer to social or academic situations for children with autism and/or emotional-behavioural needs?

\section{Methodology}

Design

The study involved children from two classes in two primary schools. The schools were chosen because the teachers had a postgraduate qualification in $\mathrm{PwC}$ that qualifies them to facilitate McCall's CoPI (McCall 2009). The teachers facilitated CoPI sessions with the whole class for an hour each week as part of normal classwork over ten weeks. An observational schedule and reflective log were used by teachers to capture information from 
CoPI sessions and in other classwork over the period. The class teachers were also interviewed. Quantitative and qualitative analysis was conducted on the data gathered.

\section{Participants}

The study comprised seventeen children with ASN from the two mainstream classes: School A and School B. There were ten participants, aged between nine and twelve, with ASN from School A in a class totalling fourteen children. The participants from School B were seven pupils, aged between nine and eleven, with ASN from a class totalling thirty-three pupils. From the seventeen participant children, six were considered to have social and communication difficulties, including three with a diagnosis of autism; three presented behavioural difficulties; and eleven experienced emotional difficulties. Children were categorised into three groups: ASD; SEBN-Affective (SEBN-A) (behaviour that was withdrawn, 'shy' or inward); SEBN-Behaviour (SEBN-B) (external 'acting-out' and disruptive behaviour).

\section{Community of Philosophical Inquiry Approach}

Community of Philosophical Inquiry (CoPI) is an approach to Philosophy with Children drawn from the work of Matthew Lipman in the United States (McCall 2009). It is a practical philosophy where participants engage in structured philosophical dialogue (Cassidy 2007; McCall 2009). Participants read a short stimulus text and ask questions arising from the reading. The CoPI facilitator records the questions and then chooses the question to be considered by the participants. The dialogue is structured in such a way that when participants want to contribute they should raise a hand and wait to be called; they will not necessarily be called in order as the facilitator works to juxtapose participants' contributions and philosophical perspectives with the goal of driving the dialogue further. When participants speak they must agree or disagree with at least one previous contribution and 
provide reasons for that agreement/disagreement. So that the dialogue is as inclusive as possible, participants are not permitted to use technical language or jargon. Participants may not refer to an authority for their reasons; they must present their own thinking, in their own words but not necessarily their own opinions. There is no search for consensus or a conclusion. It is these features, amongst others, that suggest CoPI might be an appropriate practice in supporting the participation of children with emotional-behavioural and/or communication needs.

Participants sit in a circle, allowing them to see and be seen by one another. This also ensures that no-one is set apart as an expert or excluded from the community since the seats are equidistant. The facilitator remains outside the circle of participants. In doing so, she is able to see all participants, including their body language, which may suggest a participant has something to contribute though she has not raised her hand. Importantly, too, because the facilitator removes herself from the circle, the participants speak directly to one another. The facilitator's loyalty is to the dialogue; she strives to ensure the dialogue remains as philosophical as possible in the decisions and interventions she makes (Cassidy 2012). The structure, as described above, allows that everyone is included in the initial stimulus to the session. All participants share the same text, whether read by or to them. The stimulus may be a fictional story, script, poem, song, or it may be taken from a newspaper. The facilitator takes care to record participants' questions exactly as they are asked; she does not interpret the questions.

Participants engage in philosophical dialogue using everyday language which is inclusive by its very nature. Everyone in the session must be able to understand what is being said, in terms of general vocabulary but, and perhaps more importantly, philosophically (Cassidy 2007). In other words, technical language or jargon is not permitted and words that have a particular philosophical thrust in such dialogue, for example, identity, knowledge, fairness, 
and so on, must be explained. As far as possible, the participants must speak plainly to aid comprehension in order to advance the philosophical content. There may be disagreement over how terms, phrases or words are used, but this serves to illustrate the conceptual challenges within the topic, and this is to be welcomed. This is aided by the demand to make connections to previous contributions. The 'I agree/disagree with... because...' structure ensures that each contribution builds on previous ones and the community is, by necessity, engaged in a shared search for meaning. That participants need not give their own opinions is liberating as they can experiment with ideas or explore topics they have not previously considered. It is worth noting at this stage that participation in CoPI need not involve the individual participant in speaking out; they can be part of the community by thinking about the ideas without actually articulating them to the rest of the group. Because participants cannot reference an authority for their agreement/disagreement, be that, for instance, a teacher, book, grandparent, friend or television programme, they have to think and reason for themselves. In CoPI there is no recourse to an authority for participants' reason-giving as everything is open to question. Therefore, any authority figure or source is also fallible and open to question. Similarly, links to academic philosophy are not made for the participants, though the facilitator will have a background in philosophy so that she is able to recognise it when it occurs and will know how to intervene in order to take the dialogue forward. The participants do not learning about philosophy as they might in academic philosophy; instead they interrogate the ideas in the inquiry. Over time, the participants lose ownership of their own contributions and focus on the dialogue as a shared endeavour. Without a consensus or conclusion, the dialogue can move in a range of directions and participants are not required to defend a particular position or come to one. Indeed, the search for consensus closes down philosophy and the opportunity to keep thinking about a topic afterwards is implied by there being no conclusion to a CoPI session (McCall 2009). 


\section{Measures}

Quantitative and qualitative approaches were used to gather data on the teachers' perceptions of the children's behaviour during the CoPI sessions. An observation schedule was devised to be used by the teachers in relation to the CoPI sessions. The schedule contained four categories selected to describe key elements of the children's behaviour within the CoPI experience:

1. Engaged Participation - including listening, attentive behaviour, 'on topic' interruptions (but not distractions);

2. Verbal contributions, following the structure (e.g. taking turns as invited: staying 'ontopic');

3. Tries to distract others; and

4. Patience while waiting to speak.

The extent of occurrence of these categories was scored on a three-point scale: $1=$ not at all; $2=$ sometimes; $3=$ most of the time. The scoring adopted a typical convention to ensure that it was as straightforward as possible and not overly time-consuming for the teachers.

Reflective logs were maintained by the teachers to record critical incidents (Tripp 2011) that could be attributed to the children's participation in CoPI. Semi-structured interviews were conducted with each teacher following completion of the CoPI sessions to explore and elaborate on their observations and reflections.

\section{Results}

Analysis procedure 
It was not expected that results from such an inquiry would follow a pattern of linear progression; therefore, optimal scores across the weeks were noted and average scores across the ten sessions were generated. All children attended at least seven out of ten sessions; for the SEBN-B group all children attended 10 sessions; for the ASD group two children attended 10 sessions and one child attended 7 sessions; for the SEBN-A group two children attended 8 sessions, two attended 9 sessions and the rest attended all 10 sessions.

\section{Engaged Participation}

Figure 1 shows the average score across all sessions for the Engaged Participation of the children in the CoPI sessions. The highest possible average score, using the scale noted above, for these categories was ' 3 '. The children in the SEBN-B and ASD groups had average scores between 2 and 2.9, indicating that all these children were engaged at least 'sometimes' in the sessions. It is noticeable that the lowest and highest average scores for Engaged Participation were found for children in the SEBN - A group. Notably, none of the children showed a complete lack of engaged participation across all the sessions.

\section{INSERT FIGURE 1 HERE}

\section{Verbal contribution}

Figure 2 shows the number of sessions in which the children spoke, as a percentage of the number of sessions attended. It does not show how often the children spoke in those sessions, because a child may make one exceptionally strong point or she may make several weaker points, so number of contributions is not the most informative measure. The focus in this analysis, therefore, was not on the philosophical quality of the contribution but the percentage of sessions attended in which a child made a verbal contribution. 
Most children contributed in nearly all of the sessions attended, with only three children contributing in half or fewer than half of the sessions. All of these children were in the SEBN -A group. One child with ASD contributed to $70 \%$ of the sessions attended, and all the other children in the SEBN-B and ASD groups contributed to $90 \%$ or $100 \%$ of the sessions attended.

\section{INSERT FIGURE 2 HERE}

Relevance of contributions across sessions

Average scores for rated relevance of contribution across the sessions, as shown in Figure 3, indicate that the children in the SEBN-B and ASD groups gave relevant contributions. Children in the SEBN-A group again showed the highest and lowest scores.

\section{INSERT FIGURE 3 HERE}

\section{Self-regulation - distracting others and showing patience while waiting to speak}

\section{Distraction behaviours}

For Distraction Behaviours, the score of 1 indicated that Distraction Behaviours were present 'not at all', while a score of 3 indicated that the Distraction Behaviour was 'all the time'. Average scores across all sessions for self-regulation, or lack of self-regulation in the form of trying to distract others, as shown in Figure 4, indicate that for the ASD group, the average score ranged from 'not at all' to 'sometimes' and 'all the time'. For the SEBN-B group the average scores were at the higher end, indicating that self-regulation with respect to distracting behaviours was low on average. However, no children in the SEBN-B group showed distracting behaviour all the time in all the sessions. Concomitantly, for the SEBN-A group, the majority of scores indicated that there was no distracting behaviour shown in any session. 


\section{INSERT FIGURE 4 HERE}

Patterns of distraction behaviours within the SEBN and ASD groups

Looking at patterns of distraction behaviours for the children with a high average distraction score (2-2.9) as shown in Figure 5, comprising all children in the SEBN-B group and also one child in the ASD group, it can be seen that for three children, scores lowered to just 'sometimes' as the sessions progressed. One child in the SEBN-B group showed a more varied pattern of level of distraction behaviours.

\section{INSERT FIGURE 5 HERE}

\section{Self-regulation through patience behaviours}

Figure 6 shows self-regulation behaviour in terms of average scores across sessions for waiting to speak. It can be seen that for the majority of the children in the SEBN-A group the average scores indicated that patience was exhibited all the time in all sessions. For most children in the SEBN-B and ASD groups the average score was in the 'sometimes' range, although for one child in the ASD group, the average score indicated that this behaviour happened 'all the time'. For one child in the SEBN-B group, scores for patience indicated that this behaviour on average was not shown. All children in the SEBN-B group showed variations in patience behaviours across the ten sessions.

\section{INSERT FIGURE 6 HERE}

\section{Summary of quantitative results}

As can be seen from the results above, the SEBN-B and the ASD groups showed high levels of engagement, verbal contribution and relevance of contribution across the sessions. For the SEBN-A group, however, it is noticeable that the highest and lowest levels of engagement, 
verbal contribution and relevance were found. For distraction and patience, the SEBN-A group showed high levels of patience and no distraction behaviours. The SEBN-B group showed the highest average scores for distraction. However, their patterns of distraction lowered for most of this group across the sessions. For the ASD group the distraction scores ranged from low to high. For patience, the ASD and SEBN-B group also showed high levels of patience, with only child in the SEBN-B group showing a low level of patience.

\section{Qualitative results}

Content analysis of the critical incidents recorded in the teachers' logs and interview transcripts allowed a number of examples of the impact of participation in CoPI for the children to be identified, complementing the quantitative findings. The reflective logs on occasion contain comments the teachers recorded from their colleagues and the children reporting their experiences of participating in CoPI. Collated findings, presented below under three key headings, are supplemented with illustrative examples. One teacher's log recorded a comment from the Head teacher of the school, which is additionally included below.

\section{Social interaction and participation}

In relation to social interaction, the breadth of impact of the CoPI approach for all the children involved is interesting. The teachers reported that the children's social interactions, both within and outwith the CoPI sessions, were influenced by their experience of CoPI. For one child who had a particularly difficult relationship with his sibling class-mate, there was a shift in the manner in which he dealt with her contributions during CoPI. He became able to listen to her input and engage with it in a more reflective manner, considering her points, dis/agreeing and providing reasons. Overall, the teachers reported that the children listened better as the CoPI sessions progressed. They did not interrupt and made connections with 
what was being said. Notably, one of the children with autism who required a support assistant to ensure he stayed 'on task' throughout the rest of the school week was able to participate in the sessions independently. Similarly, another child was able to remove himself from the session if he found himself unable to cope emotionally or behaviourally. More importantly, he was able to recognise when he felt able to re-join his peers to continue with the dialogue.

\section{Transfer of experience to other activities}

The impact on group work activity across all participating children was noticed by the teachers. The more reflective approach during the CoPI sessions reported above transferred into other aspects of the children's school lives. One of the children with ASD began to adopt the 'I dis/agree... because...' structure in other parts of the school day, particularly when he wanted to justify a point he was trying to make. This is similar to another child with behavioural difficulties who used CoPI to help him structure the articulation of his thoughts more precisely. Where he had previously found it difficult to organise and convey his thoughts, and would become frustrated by this, the adoption of the agree/disagree... because... structure allowed him to become more successful in articulating points he wanted to make in a variety of classroom activities.

\section{Confidence}

One child with specific emotional difficulties who, prior to the CoPI sessions, had found it very difficult to speak with her peers, over the ten weeks became much more comfortable in doing so. This was also the case for another child with emotional difficulties who could be seen taking a more assertive and leading role in group work situations where she would normally have remained silent and non-participative. Another child with emotional difficulties appeared to become more confident in group work, staying more focused and 'on 
task'. This was also evident for one of the children with ASD who, following his CoPI experience, resisted attempts from other children to distract him during class activities. In addition, one of the children with behavioural difficulties was reported to become much calmer and was less violent in the playground. The teacher was not aware of any other changes in the child's life that may have brought about this difference. In addition, one child with behavioural difficulties started to volunteer to read aloud in class; something that had not happened before the CoPI sessions.

\section{Children's views}

The teachers, in the normal course of a day, often spoke with the children about their experiences and views relating to participation in $\mathrm{CoPI}$, and the children also made unsolicited comments during the course of general conversation. The teachers noted the children's comments. Interestingly, while the teachers' records and comments showed that they were aware of the impact primarily on the children in terms of their engagement in group work activity, the children themselves thought about the impact and identified benefits more broadly, saying, for example, that 'It gets good stuff running in your head' or that 'I find it easier getting on with people when I use philosophy', with one child reporting that 'I sometimes use it because my sister thinks she's really smart and I would say I agree or disagree on your opinion'.

All the children seemed to like the structure and used it in places outside the classroom context. One child said that he used it in school and in groups outside CoPI, with others commenting that they had 'used it with my mum and dad' or 'in the playground it helps out with friends'. The idea of helping out with friends relates strongly to the positive interactions the children reported, with one child with ASD stating that 'I find it easier to get on with people when I use philosophy and just the agreeing and disagreeing in general' and another 
with behavioural difficulties noted that 'It helps me think and I don't get angry about it'. The idea of using the rules of agreeing and disagreeing outside the school context was noted by one boy who spoke about an argument in his football club and how he had suggested to the other children that they use agreeing and disagreeing, and that this had worked. For these children the structure seems to have been supportive in helping them to engage with others, with them also offering comments beyond what the teachers were observing or were able to observe.

The children found the sessions fun, with the 'thinking' being what they found enjoyable. 'It's fun, it's like you're in a game and you get a lot of information stuck in your head and you keep it going and going' is one example of how the children responded to CoPI. This was echoed by others who said, 'It's fun listening to what other people are saying'. The element of having time in the class to think was also valued by one of the children who stated, 'You need thinking time'. For one of the children with behavioural difficulties, it was clear that doing philosophy is not only supportive of the feelings of others but that it could be useful in later life when he said,

'Sometimes it's really difficult, you need to follow the story and you need to think about what the person's saying and you need to agree or disagree and you know someone's not going to get upset. If you're good at it you can have cash, wife, job, house and your philosophy will go into generations'.

\section{Head teacher's view}

In one of the schools the Head teacher was reported by the teacher as having noticed a change in some of the children who had participated in CoPI. The head teacher explained that she thought CoPI might be a useful way to support children with a range of learning difficulties and that the success, as she saw it, of using CoPI with children with ASN highlighted the 
need for a dramatic change in the ways in which such children, perhaps all children, are assessed. She recognised the value of allowing children to be freed from written assessment because she saw how effective their oral contributions were when doing CoPI and as a consequence of participating in the sessions.

\section{Discussion}

The present study offers original insight in the areas of SEBN/autism in relation to engagement and participation in the structured, dialogic practice of CoPI. There was no previous empirical work recorded of children with ASN engaging in $\mathrm{PwC}$, particularly in the area of CoPI. While the field of academic philosophy is now found in schools, and with associated research exploring a range of learning in this area, no work has been undertaken that explores practical philosophy, notably CoPI, with children who have additional support needs. It is clear from the findings that the children in the study were able to engage and participate in collaborative, philosophical dialogue. It is proposed, therefore, that the opportunity to be involved in CoPI seems to be helpful in supporting engagement and selfregulation in children identified with SEBN-A and SEBN-B and children with autism.

These children did not all participate by speaking in every session, but this would be the same for any group of participants (Cassidy 2007). Quantity of contributions was not key, as speaking often is not a guarantee of quality of contribution. Importantly, the children participated during the sessions by offering comment or by being engaged in the dialogue through their active listening (Millett and Tapper 2011). This engagement is particularly striking in demonstrating self-regulation since the teachers reported that disruptive behaviour in the SEBN-B group did not worsen during the CoPI sessions; in fact, it reduced. Any lack of self-regulation identified was reported as being a result of the children being excited and engaged with the dialogue. It appears that the structure was supportive for the behaviour and 
self-regulation of these children, as in their normal classroom setting their behaviour was reported to be much more distracting and disruptive for other children. It is not clear whether it was the structure alone to which the children responded in the instances reported; it could be that the activity itself was much more engaging than other classwork. Without the pressure of completing a given task in a particular time or recording 'correct' answers for the teacher, the children may have been more relaxed and in some ways liberated from what might be the confines of normal classroom activity. This is not to suggest that the sessions permitted children to do as they chose; rather, the sessions were very tightly bound by format and structure that was clearly different to the structures of typical classroom activities. However, during the dialogue the children generated and directed the argument. With the clear parameters set by CoPI, the children were able to experience success through others listening to them, to their ideas being taken account of in others' contributions, with the opportunity to build and expand on ideas, and the general flourishing of the dialogue.

While the children may have been carried along by the dialogue in such a way that they engaged with what was being said, it is interesting that all the children contributed to the sessions, including those with ASD for whom perspective-taking and reciprocity in conversation can be a challenge (Volkmar et al. 2014). None of the children remained silent during the sessions, and for those who offered comment, they made relevant contributions, meaning that the arguments being presented by the children were focused on the topic in hand and that in some instances were crucial in moving the dialogue forward. The children's attention had to remain focused in order to contribute a relevant or meaningful perspective, they had to attend carefully to others' contributions and they needed to make connections between the views of others and themselves. Notably, it was for children in the SEBN-A group that the lowest and highest scores for engagement were found, possibly indicating the 
breadth of characteristics for in this category, which included those who showed signs of being shy, anxious or withdrawn.

In listening to the views of others and in waiting to be chosen to speak, participants had to exhibit patience and a high level of this was observed in nearly all the children. The children with behavioural difficulties were beginning to show signs of increased patience, though, again, the study was not primarily concerned with measuring changes. It is important that the children were able to demonstrate patience, since for some this was considered problematic in the normal classroom environment. Crucially, many participants, regardless of age and experience, fail to be patient during CoPI. This does not mean that they are unable to wait their turn or that they are not listening to the dialogue, it simply means that the participant may be excited by what is going on and is enthusiastic to contribute. This impatience may be manifest by bouncing in their seat, waving their hand in the air to attract the facilitator's attention, shifting position repeatedly, or nodding or shaking their head vigorously. These behaviours are displayed by participants beyond those with SEBN-B and/or ASD. An issue might only arise if the particular participant fails to wait to be invited to speak or talks over another participant. The teachers did not report that any of the children in this study displayed impatience in a disruptive way. Indeed, the modelling of interaction and emotional self-regulation by the other children in the classes may have supported the children (Cooper and Cefai 2013). In seeing how others react when people agree or disagree, the children may observe how this works out for them and how disagreeing can be a positive initiation and might in turn trigger a positive response from the other participants. The CoPI approach could be understood to present a powerful experiential learning context for the children.

Within PwC generally, and CoPI in particular, it could be argued that participants are offered acceptance and a sense of belonging. Each contribution to the dialogue is taken as seriously as any other. Certainly, in all groups, some ideas may not be taken on by the other 
participants, but in being aired they contribute to the dialogue as they must be considered, even if rejected. That the contributions are listened to and given due consideration is likely to build confidence in participants, both in terms of engaging with others' ideas but also in presenting their own. Over time, a community evolves, with participants acknowledging and anticipating the perspectives that others may bring to the dialogue. Each child is part of the culture of ideas and communication, and so has a sense of belonging which in other contexts is often difficult to achieve for children with autism or SEBN-B.

The factor that seems to have supported the participants in this study is the tight structure of CoPI, but a structure that still allows and facilitates participants' freedom to think and articulate those ideas in a safe context where everyone must abide by the same, transparent and consistent rules (Idsoe, 2016). For the children with autism, for whom there is often the suggestion that they have difficulty in reading social cues, there is no need to predict what will happen (Quill 1995), they do not need to think about turn-taking in the same manner as in other social contexts, particularly in larger groups, because the rules are articulated to all participants at the outset and these are maintained by the facilitator. While there is some unpredictability in just when an individual will be selected to speak, the participants know they will be picked eventually. In tandem with the features of CoPI itself, the psychological processes involved when participating in the practice are important in considering the ways in which children with SEBN-A and B and autism might be supported in the mainstream classroom.

Philosophy, by its very nature, requires one to think. Beyond this, though, practical philosophy relies on reason giving and justifications for points made. The structure of the CoPI dialogue, with its 'I dis/agree with... because...' is such that it can only work if the speaker provides reasons for her contribution. This demands that speakers make connections with other participants' contributions and that the speaker has to position herself in alignment 
or in opposition to at least one other view presented. Participants need to be explicit about their thoughts and ideas. In articulating their thoughts, the need for inference on the part of the listeners is reduced. For a child with autism it may be difficult to make inferences (Wing 1996; Landa 2000). However, given the creative dimension of CoPI, where each participant must create meaning for herself as well as for the listeners when she is speaking, the need for inference pervades philosophical dialogue; constantly the participants strive to infer meaning and understanding from and about the contributions made. This means that the child with autism is supported to make inferences where she may otherwise struggle because it is the very nature of practical philosophy that arguments must be clear, thereby offering transparency for all in terms of content and structure. Further, CoPI's entirely predictable structure offers support to those children with SEBN-B who may resort to aggression due to uncertainty in normal social contexts and also for children with SEBN-A who experience anxiety or shyness.

For children with certain emotional and behavioural difficulties there are challenges in relation to their ability to take on or understand others' perspectives (Volkmar et al. 2014). CoPI demands that participants offer a perspective on a particular point, though this need not be their own personally held view. CoPI's structure enables participants to position themselves in a manner that sits counter to their own opinion, thereby allowing them to adopt another's perspective, should they so choose. Not only does this present interesting opportunities for participants to make their thinking explicit, it could enable them to develop their awareness of their own behaviour in such a context that they can begin to manage what might otherwise be a situation for potential conflict. Through CoPI, it is suggested, safe and structured opportunities to navigate and negotiate a way through conflict are presented. This is likely to lead the child to exercise patience, resulting in better emotional self-regulation. Further, participants may grow in confidence in the safe environment of CoPI where their 
views are heard and respected. The growth in confidence stems from the freedom to try out ideas that are challenged or taken up by others, that do not have to be matters of personal conviction. The ideas are treated with respectful listening by the other participants and the facilitator, thereby supporting the individual in managing her emotional behaviour and reducing opportunities for conflict.

Respectful listening is two-way and is central to the psychological processes evident in CoPI. The child who struggles to listen in other contexts must listen in order to participate in CoPI; she is given equal status in the group and will recognise that she is also being listened to. Listening is key to participation since it requires the individual to take account of others in order to engage in joint activity; one cannot participate alone. The need to work with others is important, and it is vital that the children recognise that to engage in CoPI they must collaborate, in terms of their physical behaviour towards others but also in order to generate ideas. As noted earlier, the individual, as individual, becomes overtaken by a loyalty to the dialogue itself; over time the participants lose ownership of what they say and focus instead on what is being said. For children with SEBN and autism, this can be a particularly difficult. This type of engagement is as challenging for adults new to CoPI as it is for younger participants (Cassidy 2007; McCall 2009).

Participants' voices are clearly central to their participation, and CoPI's structure may be seen to facilitate this. Voice, in this context, means two things. In the first instance, the word is employed in its everyday usage. In reading a stimulus passage aloud, each child is able to hear her voice at the beginning of the session. Being able to read either along with others or as an individual - depending on the reading ability of the participants - is important in CoPI as it supports the individuals in their first contribution to the dialogue. Alongside this, the communal nature of reading a text aloud is important in developing the context or ethos for mutual, collaborative inquiry. The second use of voice in this context pertains to 
participation in the sense of having an opportunity to have one's ideas or views heard and responded to in a positive sense - even if the response is a disagreement. For many children with ASN this is often missing in their educational lives.

\section{Conclusion}

This unique study explores the use of CoPI with children who have emotional, behavioural needs or autism. The results show that the children were able to engage in collaborative, philosophical dialogue without being any more disruptive than their classmates. The children evidently enjoyed the sessions and they and their teachers reported transferring some of the behaviour acquired through participation in CoPI into other aspects of their school and family lives. The children responded well to the opportunity to air their views in a respectful and interested way. The findings of this study lead to the assertion that it is the structure of CoPI that supported the children's engaged participation and self-regulation and that this might usefully be considered in creating classroom activities.

It can be seen, therefore, that the structure of $\mathrm{CoPI}$, the rules, the need to make connections, the opportunity for everyone to be heard, the demand for listening and responding to others, the transparency of thinking, the sense of community, and the children's ownership of the dialogue promotes the voices and supports children with SEBN or autism in the mainstream classroom. In addition, as the head teacher in one school suggested, it may be that assessment practices that rely heavily on individual, written work may have to be reconsidered for all children. A practice such as CoPI evidences that children who may normally find such assessment challenging are able to engage in an activity that demands attention, participation and self-regulation. It is in this context that our recommendation comes: that a dialogic approach such as that described by CoPI is one that can easily be integrated into normal 
classroom practice and one to which we would direct practitioners in supporting all children and not only those who may find many classroom activities challenging.

\section{Acknowledgements}

This work was supported by the General Teaching Council for Scotland under the Teacher Researcher Programme.

\section{Disclosure statement}

There are no conflicts of interest in relation to this study.

\section{References}

Cassidy, C. 2007. Thinking Children. London: Continuum.

Cassidy, C. 2012. “Questioning Children.” Thinking: the Journal of Philosophy for Children 20 (1\&2): 62-68.

Cassidy, C. and D. Christie. 2014. "Community of Philosophical Inquiry: Citizenship in Scottish Classrooms." Childhood \&Philosophy 10 (19): 33-54.

Christie, D., A. Tolmie, A. Thurston, C. Howe and K.J. Topping. 2009. “Supporting Group Work in Scottish Primary Classrooms: Improving the Quality of Collaborative Dialogue.” Cambridge Journal of Education 39 (1): 141-156. doi: 10.1080/03057640802702000

Colom, R., F. García-Moriyón, C. Magro and E. Morilla. 2014. “The Long-term Impact of Philosophy for Children: a Longitudinal Study (Preliminary Results).” Analytic Teaching and Philosophical Praxis 35 (1): 50-56.

Daniel, M-F. 2008. "Learning to Philosophize: Positive Impacts and Conditions for Implementation. A Synthesis of 10 Years of Research (1995 - 2005).” Thinking 18 (4): 36-48. 
Daniel, M-F. and E. Auriac. 2011. "Philosophy, Critical Thinking and Philosophy for

Children. Educational Philosophy and Theory 43 (5): 415-435. doi: 10.1111/j.14695812.2008.00483.x.

Department of Education. 2016. Mental Health and Behaviour in Schools. Information and Tools for Schools. www.gov.uk/government/publications

Donaldson, G. 2011. Teaching Scotland's Future. Report of a Review of Teacher Education in Scotland. Edinburgh: Scottish Government.

Education Review Office. 2016. Wellbeing for Success: A Resource for Schools. Wellington: Education Review Office.

Education Scotland. 2010. Journey to Excellence - An Introduction to Inclusion: Achieving Success for All Learners. www.educationscotland.gov.uk/images/FocusingOnInclusion García-Moriyón, F., I. Rebollo and R. Colom. 2005. "Evaluating Philosophy for Children: A Meta-Analysis." Thinking: The Journal of Philosophy for Children 17 (4): 14-22.

Gregory, M. 2008. "Philosophy in Schools: Ideals, Challenges and Opportunities." Critical \& Creative Thinking 16 (1): 5-22.

Gorard, S., N. Siddiqui and B. Huat See. 2015. Philosophy with Children: Evaluation Report and Executive Summary. London: Education Endowment Fund.

Her Majesty's Inspectorate of Education. 2011. Count Us In: Mind Over Matter. Supporting and Promoting Mental and Emotional Wellbeing.

http://www.hmie.gov.uk/documents/publication/mom-01.pdf 
Humphrey, N., C. Bond, J. Hebron, W. Symes and G. Morewood. 2015. Improving Experiences and Outcomes of Education for Learners with Autism. In Autism and Education, edited by N. Humphrey, vii-xix. London: Sage.

Idsoe, E.M.C. 2016. “The Importance of Social Learning Environment Factors for Affective Well-being Among Students.” Emotional and Behavioural Difficulties 21 (2): 155-166. doi: $10.1080 / 13632752.2015 .1053695$.

Layard, R. and J. Dunn. 2009. A Good Childhood: Searching for Values in a Competitive Age. The Landmark Report for The Children's Society. London: Penguin Books.

Lipman, M. 1988. Philosophy Goes to School. Philadelphia, PA: Temple University Press. Lipman, M. 1995. "Moral Education Higher-order Thinking and Philosophy for Children.” Early Child Development and Care 107 (1): 61-70. doi: 10.1080/0300443951070108.

Lipman, M. 2003. Thinking in Education (2 ${ }^{\text {nd }}$ edition). New York: Cambridge University Press.

Lyons-Ruth, K. 1996. “Attachment Relationships Among Children With Aggressive Behavior Problems: The Role of Disorganized Early Attachment Patterns.” Journal of Consulting and Clinical Psychology, 64 (1): 64-73.

McCall, C. 1991. Stevenson Lectures on Citizenship. Glasgow: Glasgow University Press.

McCall, C. 2009. Transforming Thinking. London: Routledge.

Marwick, H. and Sosu, E. 2014. "Predictors of additional support needs (ASN) in Scottish schools." Paper presented at the European Early Childhood Educational Research Association Conference, Crete, September 7-10. 
Moscardini, L. 2013. “Additional Support Needs.” In Scottish Education (Fourth Edition):

Referendum, edited by T.G.K. Bryce, W.M. Humes, D. Gillies and A. Kennedy, 796-808.

Edinburgh: Edinburgh University Press.

OECD (Organisation for Economic Co-operation and Development). 2009. Doing Better for Children. OECD Publishing.

OECD (Organisation for Economic Co-operation and Development). 2012. Equity and Quality in Education: Supporting Disadvantaged Students and Schools. OECD Publishing. https://dx.doi.org/10.1787/9789264130852-en

Ontario Ministry of Education. 2016. Well-being in Our Schools: Strength in Our Society. Ontario: Ministry of Education.

Phillips, C. 2012. "Socratic Inquiry for All Ages." Childhood \& Philosophy 8 (15): 131-151. URL: http://www.e-publicacoes.uerj.br/index.php/childhood/article/view/20741/15077

Quill, K. A. 1995. Teaching Children with Autism: Strategies to Enhance Communication and Socialization. New York: Delmar.

Schertz, M. 2007. “Avoiding 'Passive Empathy' with Philosophy for Children.” Journal of Moral Education 36 (2): 185-198. doi: 10.1080/03057240701325308.

Scottish Executive. 2004. A Curriculum for Excellence. Edinburgh: Scottish Executive. Scottish Government. 2012. Supporting Children's and Young People's Learning: A report on progress of implementation of the Education (Additional Support for Learning) (Scotland) Act 2004 (As Amended). www.gov.scot/Publications/2012 
Topping, K. J. and S. Trickey, S. 2007a. "Collaborative Philosophical Enquiry for School Children: Cognitive Effects at 10-12 Years.” British Journal of Educational Psychology 77 (2): 271-288. doi: 10.1348/000709906X105328.

Topping, K. J. and S. Trickey. 2007b. "Collaborative Philosophical Enquiry for School Children: Cognitive Gains at Two-year Follow-up.” British Journal of Educational Psychology 77 (4): 787-796. doi: 10.1348/000709907X193032.

Topping, K.J. and S. Trickey. 2014. "The Role of Dialog in Philosophy for Children.” International Journal of Educational Research 63: 69-78. doi: 10.1016/j.ijer.2013.01.002.

Trickey, S. 2008. “"More than Cognitive': Reflections on the Components of the Clackmannanshire Thinking Project. Critical \& Creative Thinking 16 (1): 23-43.

Tripp. D. 2011. Critical Incidents in Teaching. Developing Professional Judgement. London: Routledge.

UNICEF. 2013. Child Well-being in Rich Countries: a Comparative Overview. Innocenti Report Card 11. Florence: UNICEF Office of Research.

Volkmar, F., M.Siegal, M. Woodbury-Smith, J.McCracken, M.State, and the AACAP Committee on Quality Issues. 2014. "Practice Parameter for the Assessment and Treatment of Children and Adolescents with Autism Spectrum Disorder.” Journal of the American Academy of Child and Adolescent Psychiatry. 53 (2): 237-257. doi: 10.1016/j.jaac.2013.10.013. Wing, L. (1996). The Autistic Spectrum. London: Constable. 


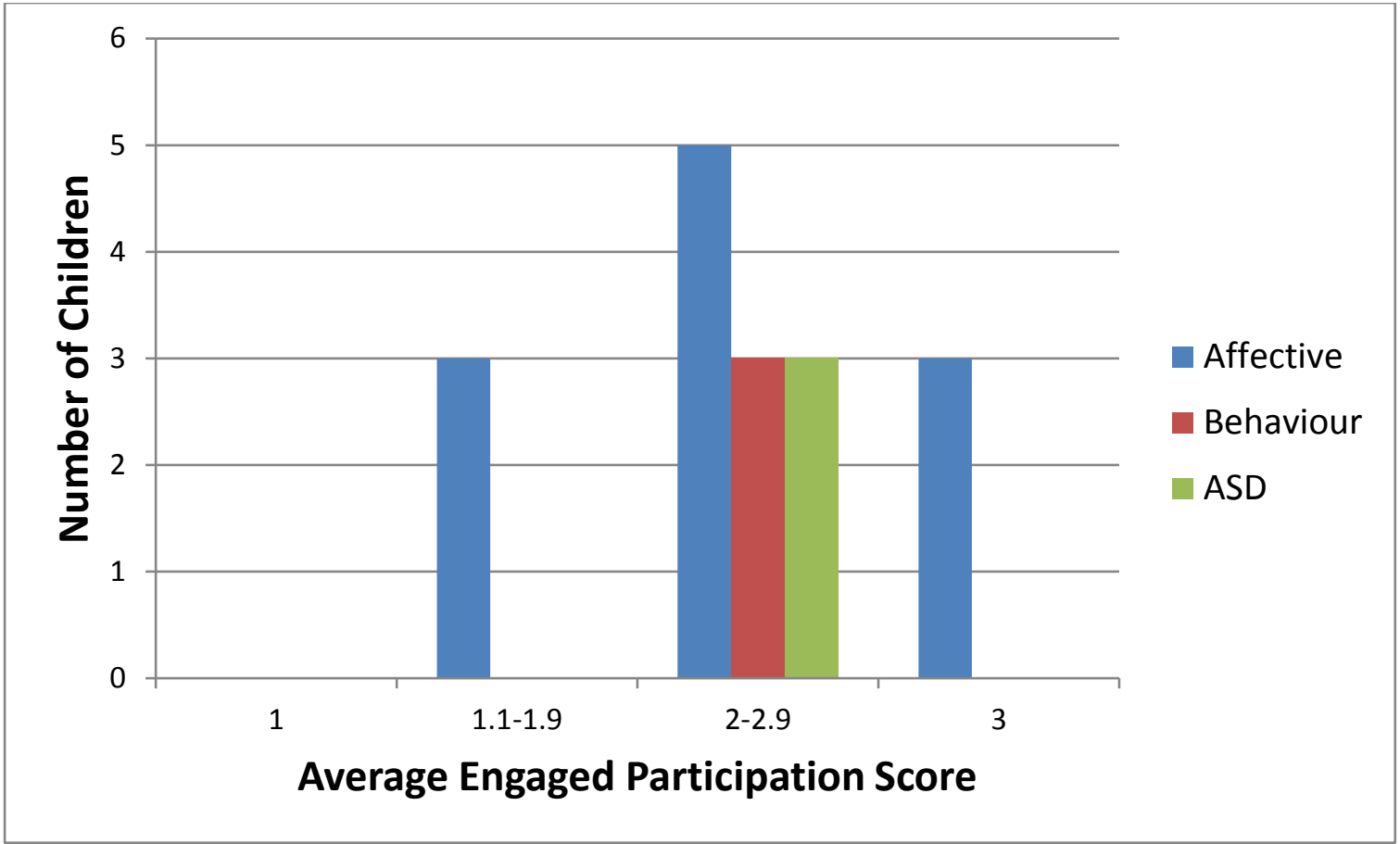

Figure 1. Number of children demonstrating different levels of Engaged Participation in CoPI sessions, expressed as an average score across all sessions attended. 


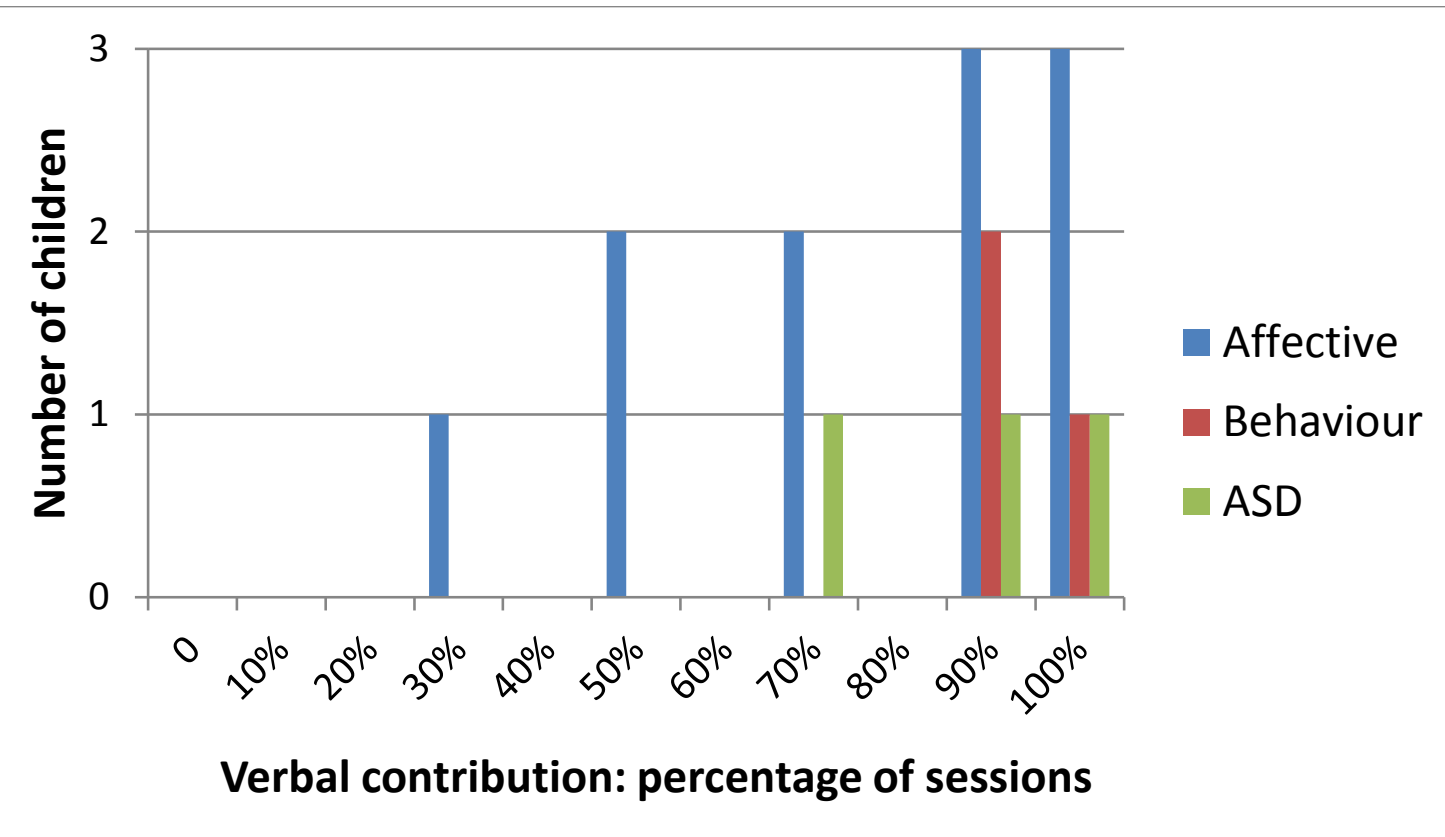

Figure 2. Number of children making different levels of Verbal Contribution, expressed as the percentage of sessions in which they made a verbal contribution to the dialogue. 


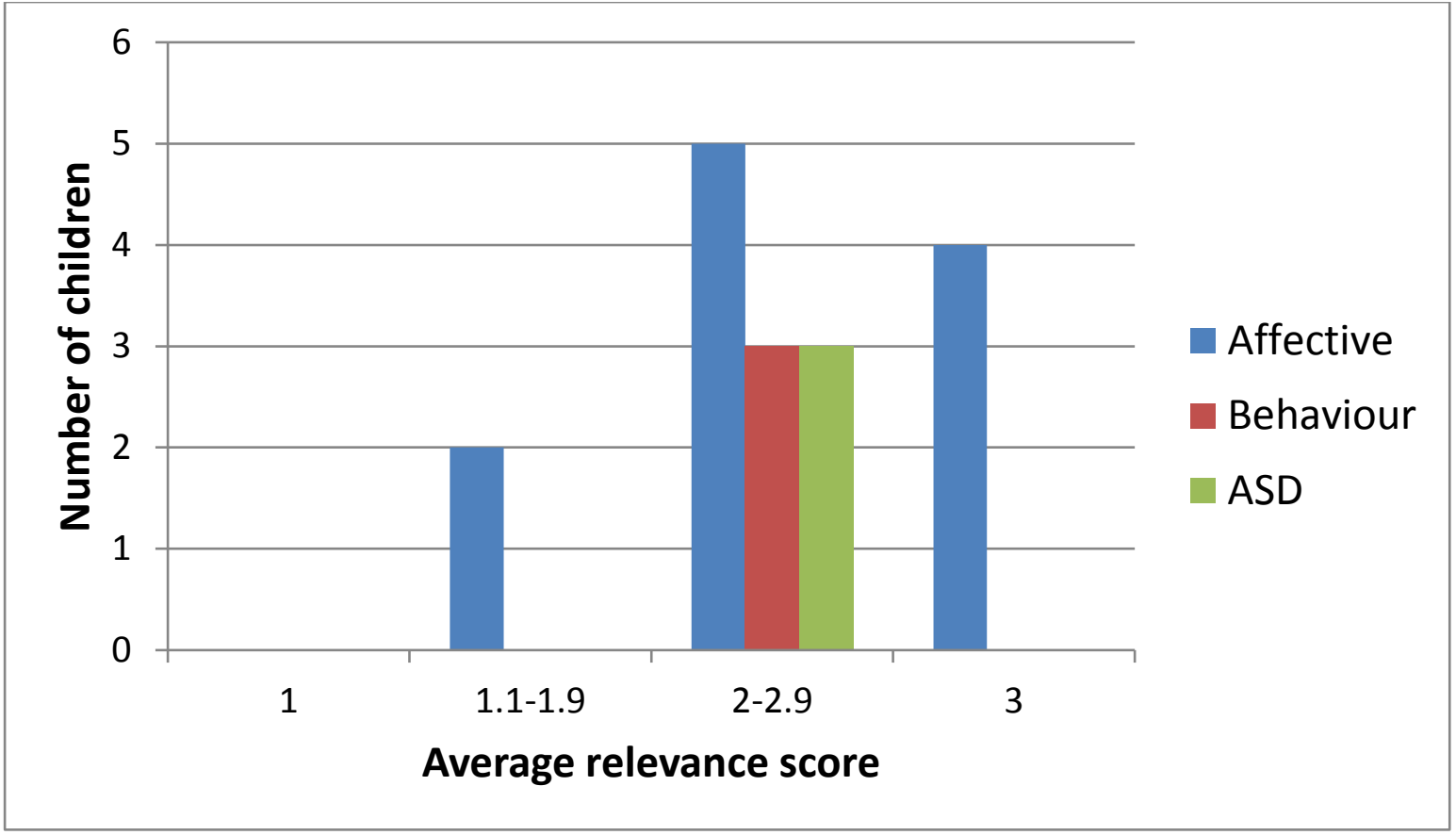

Figure 3. Number of children demonstrating different levels of Relevance of Contribution, expressed as an average score across sessions attended. 


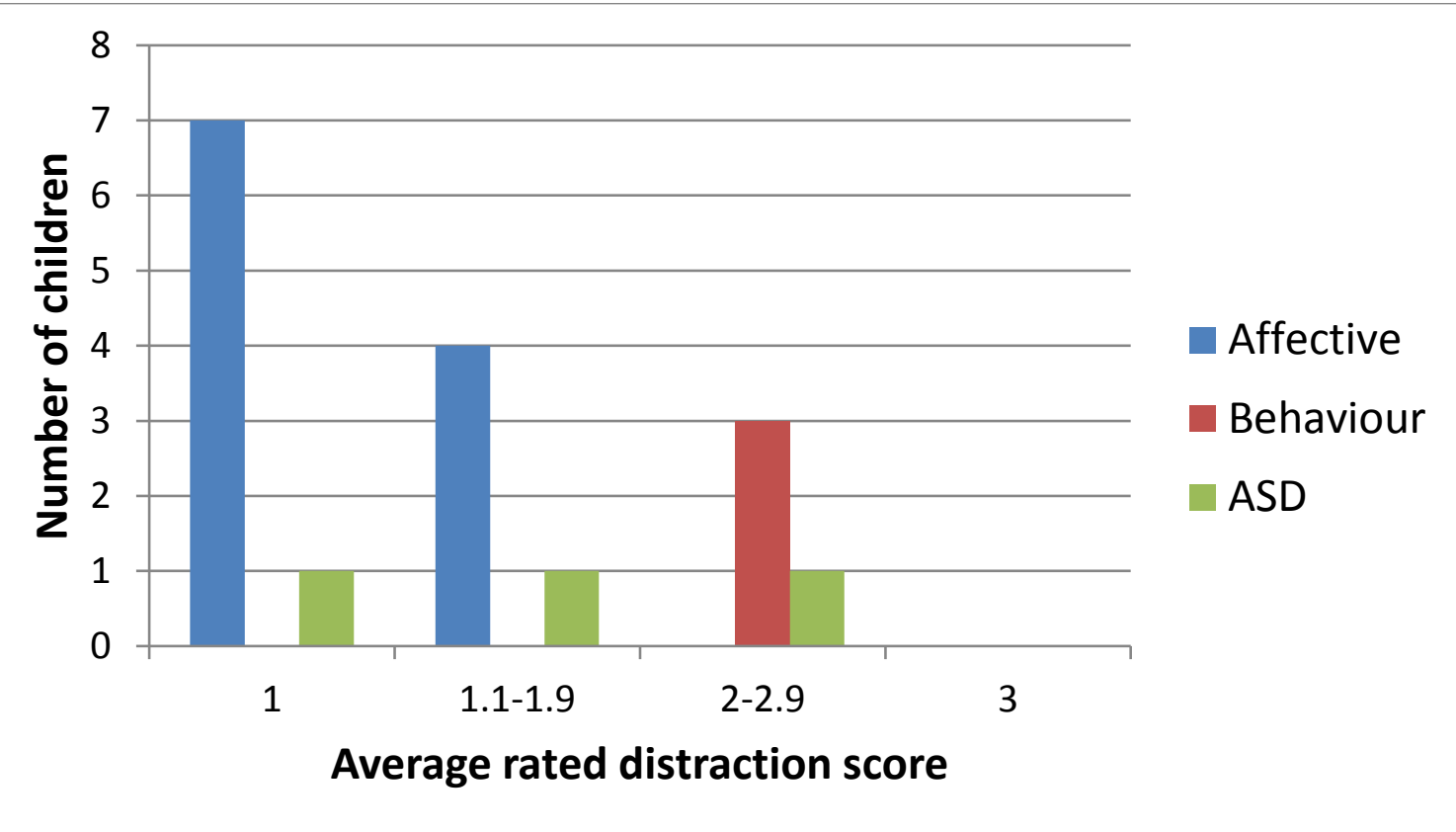

Figure 4. Number of children exhibiting different levels of Distraction Behaviour, expressed as an average rating across sessions attended. ( $1=$ "Not at all") 


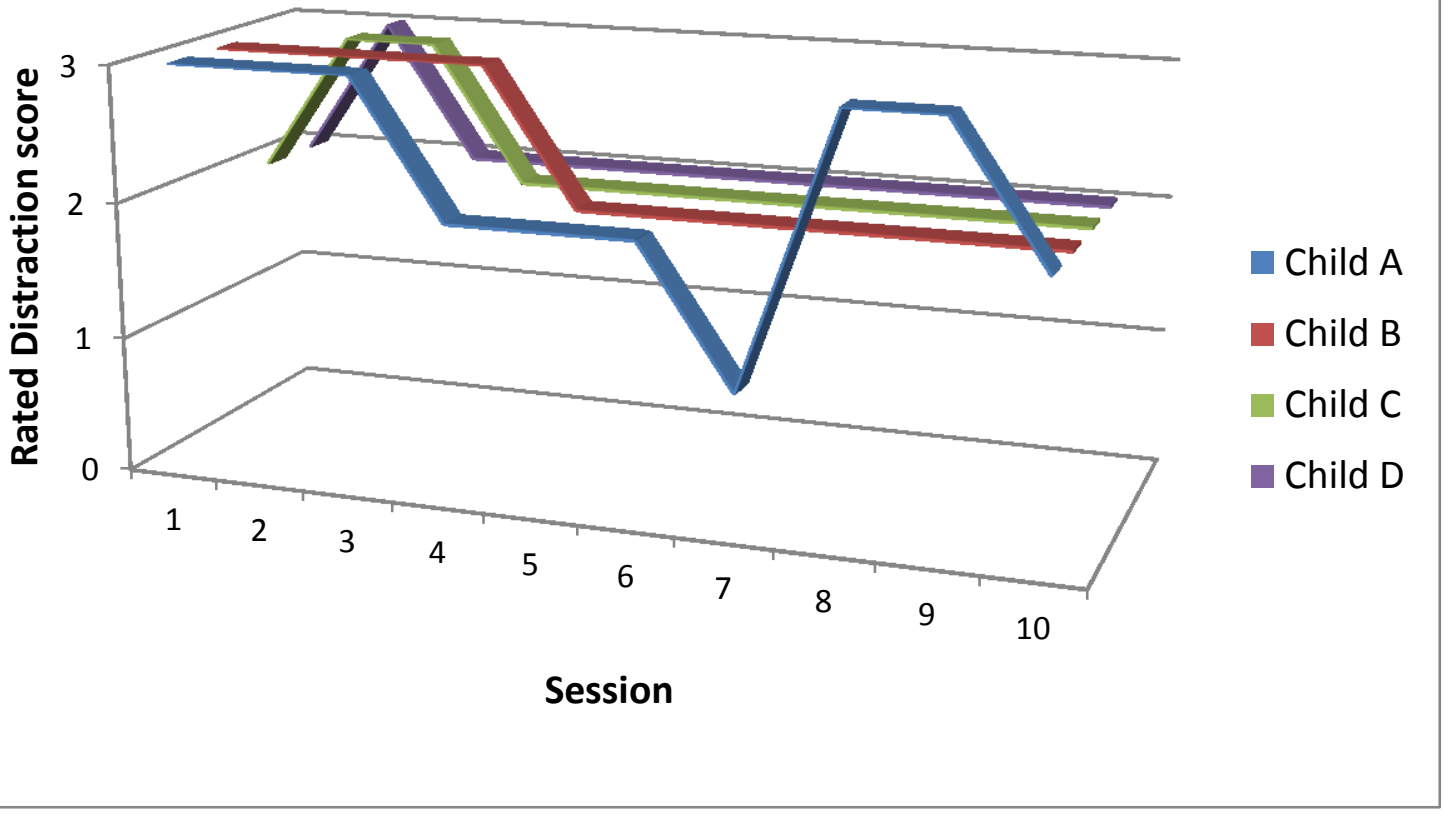

Figure 5. Frequency of rated Distraction Behaviour in each session attended by the five children exhibiting high average level of distraction behaviour. 


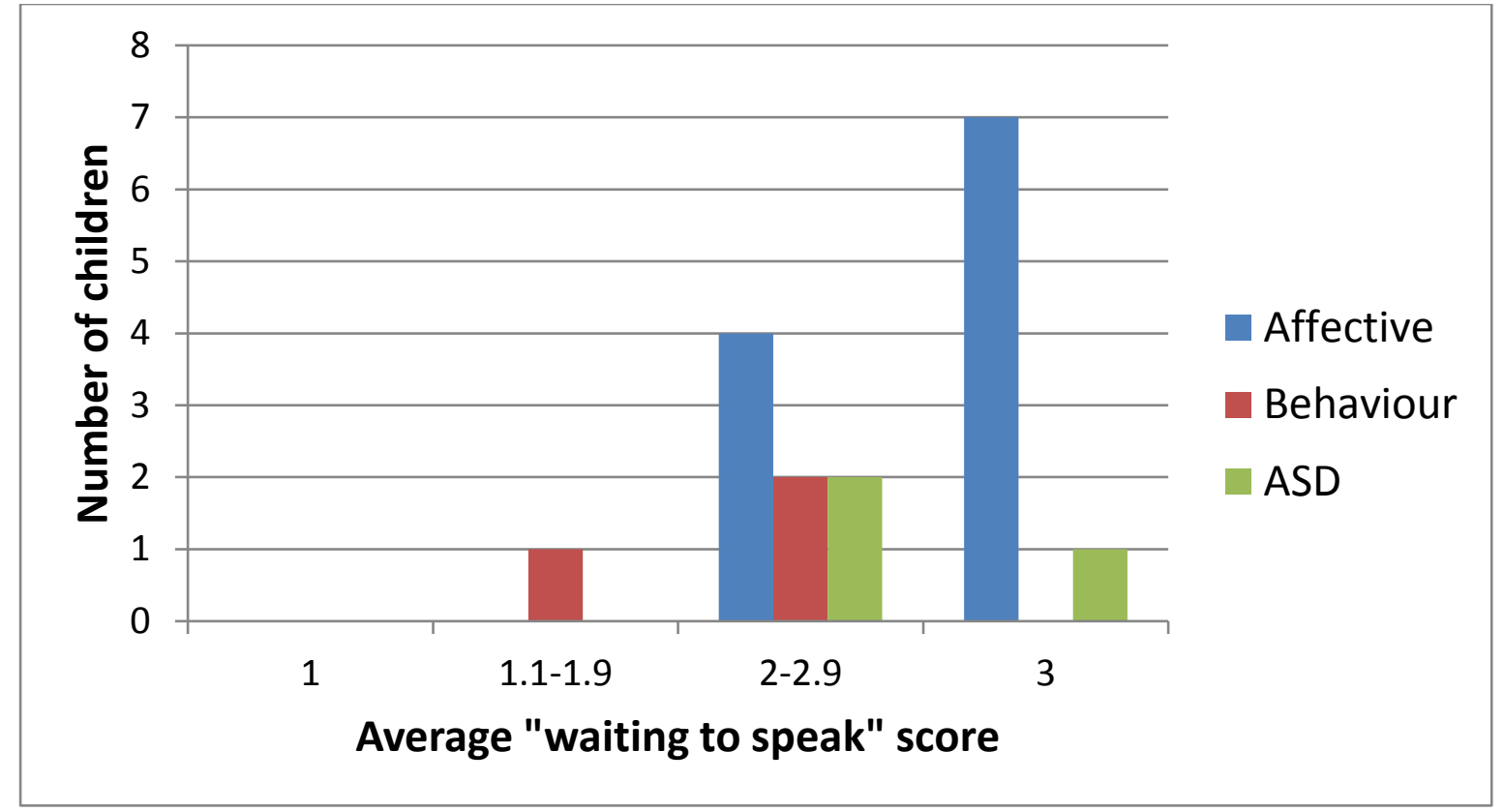

Figure 6. Number of children demonstrating different degrees of self-regulation behaviour in terms of average scores across sessions for Waiting to Speak. 


\section{List of Figure Captions}

Figure 1. Number of children demonstrating different levels of Engaged Participation in CoPI sessions, expressed as an average score across all sessions attended.

Figure 2. Number of children making different levels of Verbal Contribution, expressed as the percentage of sessions in which they made a verbal contribution to the dialogue.

Figure 3. Number of children demonstrating different levels of Relevance of Contribution, expressed as an average score across sessions attended.

Figure 4. Number of children exhibiting different levels of Distraction Behaviour, expressed as an average rating across sessions attended. $(1=$ "Not at all" $)$

Figure 5. Frequency of rated Distraction Behaviour in each session attended by the five children exhibiting high average level of distraction behaviour.

Figure 6. Number of children demonstrating different degrees of self-regulation behaviour in terms of average scores across sessions for Waiting to Speak. 